\title{
Fatigue Performance of CFRP-Strengthened Rib-to-Diaphragm Welded Details of Orthotropic Steel Decks: Experimental and Numerical Evaluation
}

\author{
Yongsheng Song $\mathbb{D}^{1},{ }^{1}$ Youliang Ding, ${ }^{2}$ Fei Jiang, ${ }^{2}$ Zhe Wang, ${ }^{2}$ Huijuan Jia, ${ }^{1}$ Zhiyuan Chen, ${ }^{3}$ \\ Chen $\mathrm{Xu}{ }^{1}$ and Jingwen $\mathrm{Ge}^{1}$ \\ ${ }^{1}$ Jinling Institute of Technology, Nanjing 211129, China \\ ${ }^{2}$ Southeast University, Nanjing 211189, China \\ ${ }^{3}$ Changzhou Institute of Technology, Changzhou 213032, China
}

Correspondence should be addressed to Yongsheng Song; songys@jit.edu.cn

Received 14 December 2021; Accepted 14 January 2022; Published 17 February 2022

Academic Editor: Dimitrios G. Pavlou

Copyright (c) 2022 Yongsheng Song et al. This is an open access article distributed under the Creative Commons Attribution License, which permits unrestricted use, distribution, and reproduction in any medium, provided the original work is properly cited.

\begin{abstract}
Rib-to-diaphragm welded details of orthotropic steel decks (OSDs) are susceptible to fatigue cracking. To deal with such cracking problem, a strengthening method using externally bonded carbon fiber-reinforced polymer (CFRP) plates was investigated by fatigue experiment and numerical evaluation. A full-scale OSD specimen with two ribs and two diaphragms was tested to evaluate fatigue cracking behavior, as well as the stress before and after strengthening. An experimentally validated numerical model was established to confirm the optimal opportunity for CFRP strengthening. The influence of different CFRP strengthening measures were then discussed on the stress intensity factors at crack tips. It was shown that bonding of CFRP plates can significantly reduce stress of rib-to-diaphragm welded details. The best opportunity for CFRP strengthening is selected as the length of crack reaches at $25.00 \mathrm{~mm}$ where the amplitude of stress intensity factor is the smallest. The attachment of CFRP plates by bonding on the surface of cracked plates can reduce stress response at cracked region by more than $30 \%$. The length of crack is of no flat growth until the total number of loading cycle after strengthening arrived at 0.8 million. Results of SIFs calculated by numerical model dropes after strengthening with reduction rate more than $35 \%$ and $18 \%$ at two crack tips and crack midpoint, respectively. Compared to the geometric dimensions of CFRP, the elastic modulus of CFRP and glue layer shows more significant influence on the fatigue performance of Rib-to-diaphragm welded details due to their stronger restraint to the propagation of crack peaks. This study provided a technical reference to the design and actual application of CFRP in the strengthening of welded details in OSDs.
\end{abstract}

\section{Introduction}

Orthotropic steel decks (OSDs) have been widely applied in steel bridges due to their various advantages, such as light weight, convenience in construction and high load-carrying capacity $[1,2]$. However, OSDs have suffered from fatiguecracking problems at some typical welded joints under repeating traffic loading. During the past decades, fatigue cracking in OSDs has been reported frequently around the world [3-6]. Among the fatigue phenomena observed in OSDs, the fatigue cracks at rib-to-diaphragm welded joints are the most common ones, as shown in Figure 1. To reduce the total length of welding lines, the diagram plates are designed with holes to ensure the passage of longitudinal ribs without cutting off, by which only $2 / 3$ height of rib's web plates are welded with the diagram plates. Due to small out-of-plane stiffness of longitudinal ribs and diagram plates, the rib-todiagram welded joints suffer from complex stress condition under great out-of-plane deformation. Thanks to the opening holes and the vertical intersection between ribs and diaphragms, the effect of stress concentration and secondary stress are exacerbated, and thus premature cracks are prone to occur. 


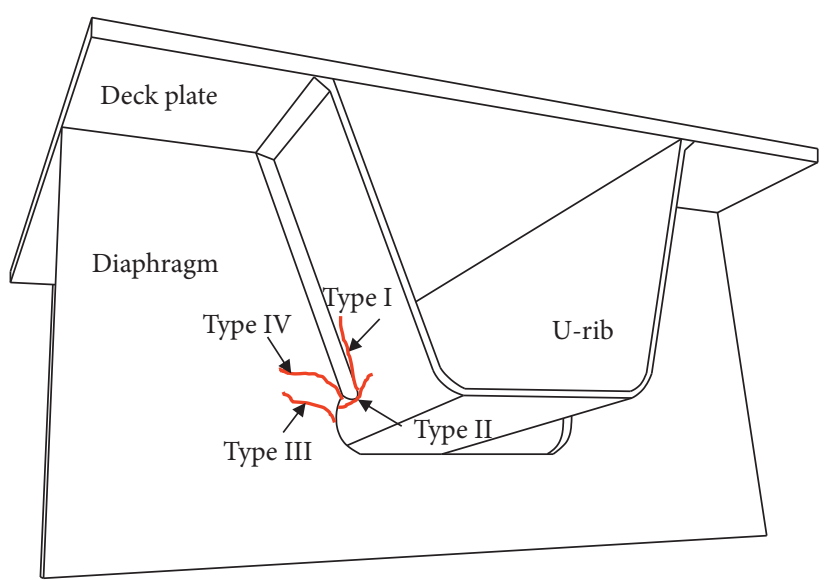

FIgURE 1: Typical cracks at rib-diaphragm welded joints.

Numerous methods and measures have been introduced and applied to try to solve fatigue-cracking problem in existing steel bridges. Drilling holes [7] at the crack tips is considered to be effective to stop cracks' propagation temporarily, but new cracks may occur at the edge of holes within a short period. Grinding [8] and peening [9] near the welds were two beneficial ways to reduce the mean stress by introducing residual compressive stress. The introduction of residual compressive stress can postpone occurrence of fatigue cracking, but residual compressive stress was released once cracking happens and the propagation rate of cracks approximate to the untreated welded joints. Attaching steel or fiber-reinforced polymer (FRP) materials by bolting or bonding on the surface of existing steel structures can reduce stress intensity by improving local stiffness of welded joints [10-19], which have been regarded as cold reinforcement as a result of no welding. Compared with steel material, the FRP materials are more completive for some advantages of low weight, convenience in fixing and elimination of corrosion problem. Therefore, bonding FRP on the external surface of structural members has been investigated as the effective strengthening method.

There are many studies on the fatigue performance of unwelded region strengthened by FRP material, and relative achievements have been applied in the actual project widely $[11,14,15,20-22]$. Fewer studies have been conducted on the fatigue behavior of FRP-strengthened welded joints. Among these studies, repair effect of FRP materials in form of plate and sheet have been investigated and examined, respectively. Nakamura et al. [23] conducted fatigue tests to study the fatigue performance of cracked longitudinal welded joints strengthened by FRP plates, and proved that bonding FRP plates can significantly reduce the propagation rate of cracks and extend the remaining fatigue life as well. In combination of fatigue test and numerical simulation, Chen et al. [24] examined fatigue strengthening effect of CFRP sheets on the cracked cross welded joints, and found that extensive bonding of CFRP sheets can improve the fatigue life by more than $15 \%$. However, Wang et al. [20] proved that CFRP plates had better strengthening effect by means of fatigue test and numerical analysis, and the fatigue repair effectiveness of the specimens was affected by configurations of CFRP material extraordinarily.

As typical structure sustaining out-of-plane deformations, FRP plates have been proved efficient to repair cracked OSD welded joints either [25-28]. Strengthened by externally bonded FRP angles, the life of rib-to-deck welded joints can be extended as long as 4.18 times, and the strengthening effects greatly depended on the FRP materials, adhesives, and angle dimensions used. However, rib-to-diaphragm welded joints has more complex stress conditions, and the dispersion of cracking behavior is even more serious. Although previous investigations have provided some attempts to improve fatigue life of OSD, few investigations were focused on the influence of strengthening parameters on remaining life of OSD. In addition, the most important or sensitive factors are not discussed and studied. To provide an effective and convenient measure to mitigate cracking at rib-to-diaphragm welded joints, fatigue test on one full-scale OSD specimen was carried out to examine strengthening effect of bonding CFRP plates. The influence of different FRP materials, adhesives and plate dimensions were investigated numerically.

\section{Fatigue Test}

2.1. OSD Specimen. One full-scale OSD specimen was designed to carry out fatigue test. The specimen was fabricated to have identical dimensions and geometries as the OSD panel for the Hong Kong-Zhuhai-Macao Bridge. The configuration of the tested specimen was shown in Figure 2. As shown in the figure, the specimen consists of one deck plate, two diagram plates and two U-ribs, where the width, length and height of it were $1200 \mathrm{~mm}, 2900 \mathrm{~mm}$ and $600 \mathrm{~mm}$, respectively. The specimen is divided longitudinally into three segments, where the spacing between two diagram plates was $2300 \mathrm{~mm}$ with two side cantilever lengths of $300 \mathrm{~mm}$. The thickness of the deck plate and U-ribs were $18 \mathrm{~mm}$ and $8 \mathrm{~mm}$, respectively. To prevent buckling under repeating vertical loading, two ribbed stiffeners with thickness of $14 \mathrm{~mm}$ were installed by welding to each diagram plate in longitudinal direction. In order to facilitate the location of cracking, eight rib-diaphragm welded joints 


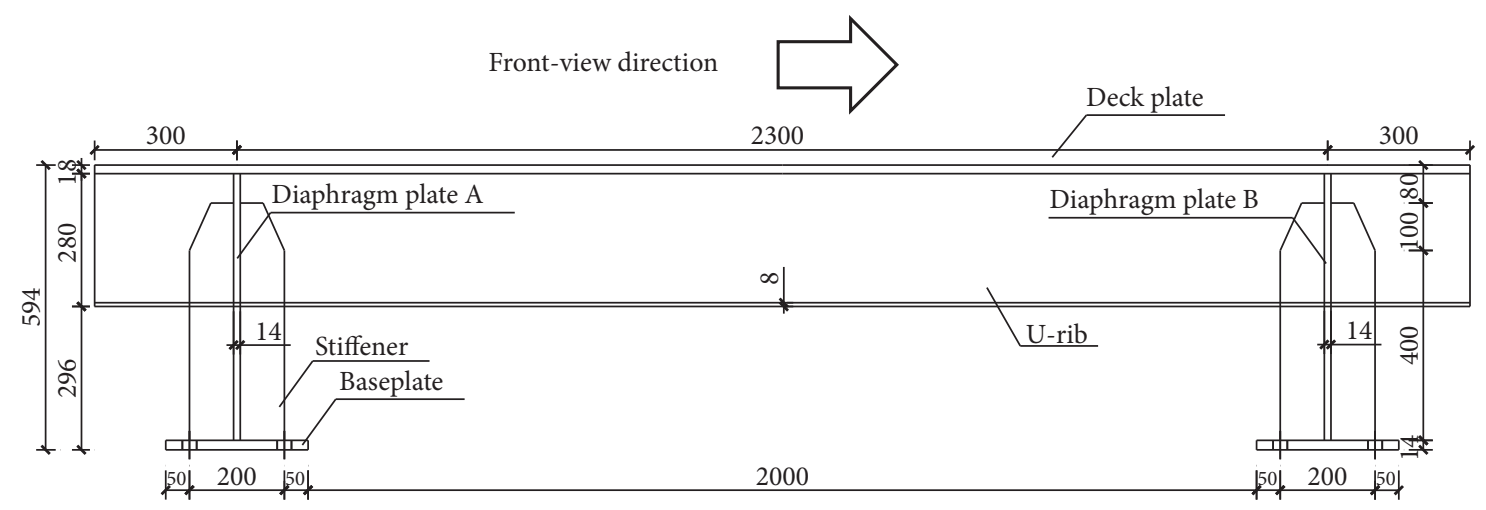

(a)
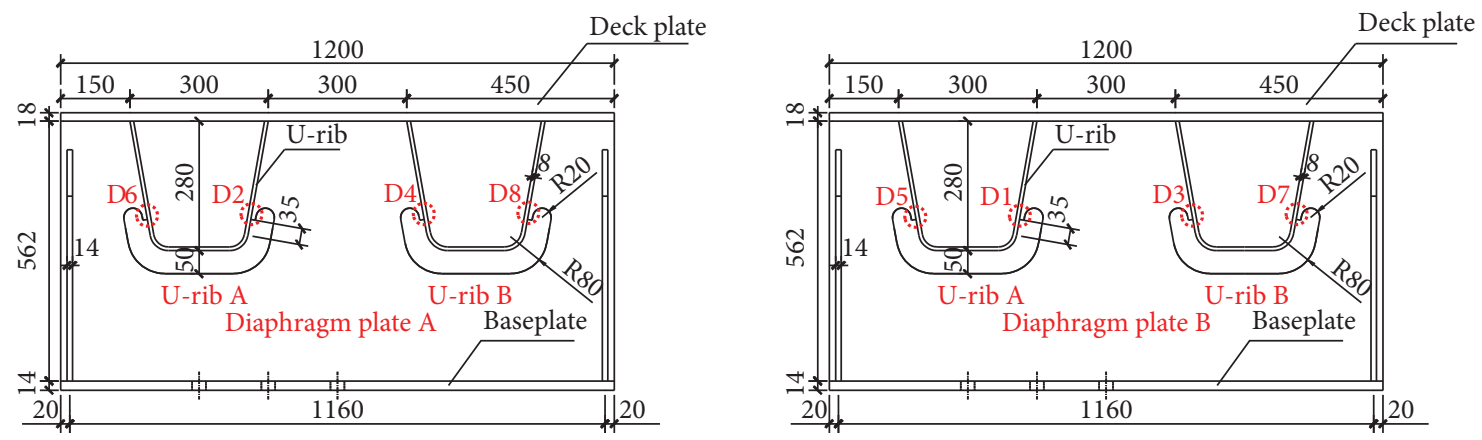

(b)

FIGURE 2: Configuration of OSD specimen (unit: mm). (a) Side view. (b) Front view.

were named from D1 to D8, whose locations were shown in Figure 2 either. The specimen was made of Grade Q345B steel, whose chemical contents and mechanical properties are listed in Table 1.

2.2. Test Setup. As shown in Figure 1, four types of cracks have been found in actual projects at the rib-diaphragm welded joints. Among them, Type II was the most observed cracks whose occurrence reduced the stiffness of U-rib's web plate, and the fatigue resistance of deck system degraded with it. It has been studied by numerical simulation that the initiation and propagation of Type II was controlled by stress condition corresponding to vehicle loading acting at the mid-span cross section [29]. Therefore, some experimental studies have selected the mid-span cross section as the position of fatigue loading of OSD specimens [29]. The cracking phenomenon of these experiments showed that the fatigue cracking procedure as well as the crack form were similar to actual projects.

In this article, scheme of single-point loading with constant amplitude was selected in the fatigue test. Figure 3 shows configuration of the test setup, where two U-ribs were named as U-rib A and U-rib B. As shown in Figure 3(a), the specimen was bolted to the testing platform, and a 54- $\mathrm{mm}$ thick square rubber plate was placed on the top of deck plate to simulate load from the vehicle. The side length of the square rubber plate was applied as $400 \mathrm{~mm}$ [30]. The singlepoint testing load was transferred from the actuator to the rubber plate through a rigid frame to realize a uniformly
TABLE 1: Chemical contents and mechanical properties of the Q345B steel.

\begin{tabular}{lc}
\hline Material properties & Value \\
\hline Carbonium & $0.18 \%$ \\
Sulfur & $0.016 \%$ \\
Phosphorus & $0.025 \%$ \\
Manganese & $0.78 \%$ \\
Yield stress & $350 \mathrm{MPa}$ \\
Tensile strength & $510 \mathrm{MPa}$ \\
Young's modulus & $206 \mathrm{GPa}$ \\
Elongation & $4.0 \%$ \\
\hline
\end{tabular}

distributed pressure on the deck plate. As shown in Figure 3(b), the constant-amplitude loading had a load range of $240 \mathrm{kN}$ with loading frequency of $4 \mathrm{~Hz}$, where the minimum value and the maximum value were $-260 \mathrm{kN}$ and $-20 \mathrm{kN}$, respectively.

To monitor dynamic strain responses of specimens during fatigue tests, uniaxial strain gages, with a sampling frequency of $100 \mathrm{~Hz}$, were attached to U-ribs. Four strain gauges were first installed at each welded joints, where three were at the rib plates and one was at diaphragm plate. If visible cracks occur, ten additional sensors would be added for the cracking details. The configuration and codes of strain sensors for welded details with and without cracking is shown in Figure 4.

2.3. Results before Strengthening. A portable electron microscope with magnification of 1000.0 and the minimum 


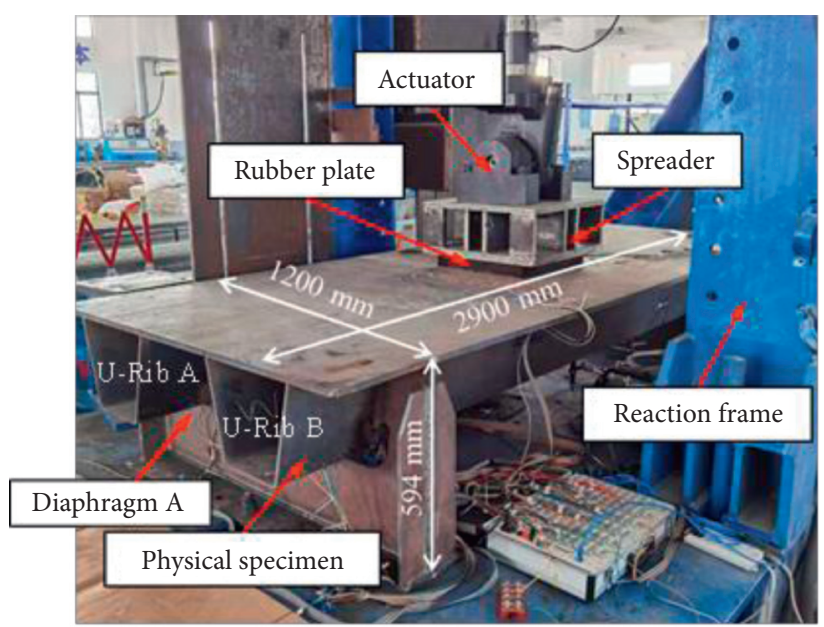

(a)

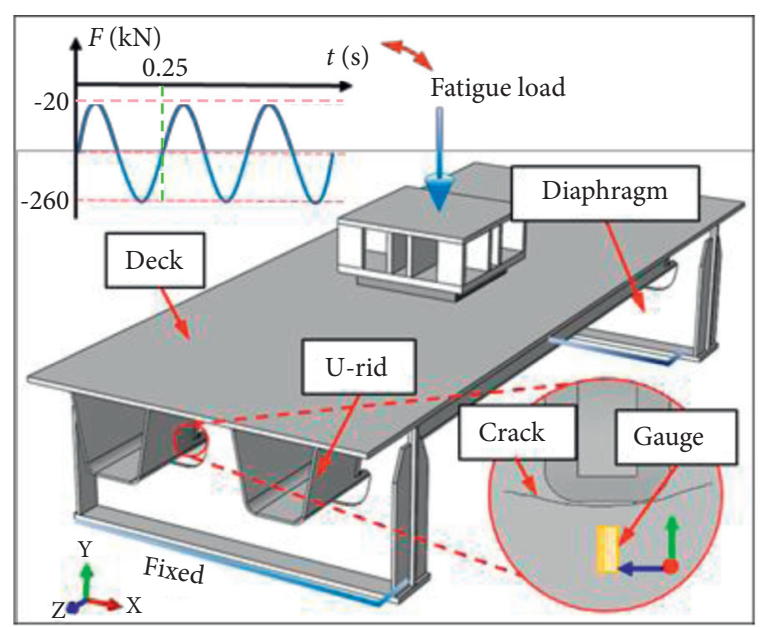

(b)

Figure 3: Fatigue test setup. (a) Physical specimen. (b) Virtual model.

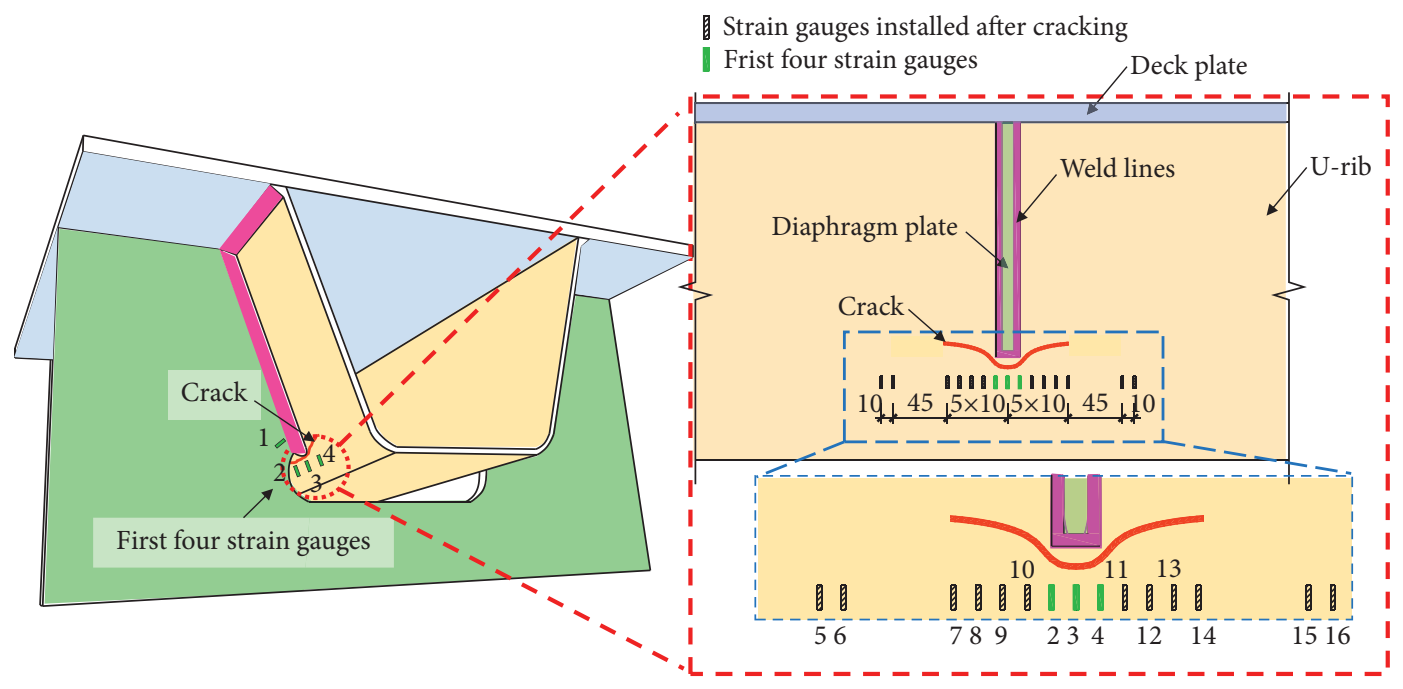

FIGURE 4: Configuration of strain gauges.

size of $0.1 \mathrm{~mm}$ was used to observe and measure length of cracks. During the fatigue test, only D2 and D3 welded joints were found cracking at the toe of welds between rib plates and cross-beams plates, and there was only one crack for each welded joint. The profile of cracks was shown in Figure 4 either. Figure 5 presents curves of length, as well as propagation rate, of two cracks along with the number of load cycle. It is shown in the figure that the procedure of crack propagation is divided into four stages. In the first stage, visible cracks were born and propagated with great growth rate with 200 to 250 thousand cycles. The rate of crack propagation was reduced partly in the second stage for about 100 thousand cycles. With the number of load cycle increasing persistently, the propagation rate begun to increase for about 200 thousand cycles. Finally, the crack propagation became slow again and the rate was getting smaller, where the crack length maintained constant as the number of load cycle arrived at 1.1 million.
As the strain decrease of Gauge 8 at D2 and D3, which were labeled as D2-8 and D3-8, possess the most significantly, they were selected to profile the variation of stress during the propagation of fatigue cracks. Figure 6 presents curves of stress amplitude at these two positions along with the number of load cycle. As shown in the figure, the stress amplitude at both positions varied from tensile to compressive with the increase of number of load cycle. The decrease rate of stress amplitude was great at the first stage of crack-propagation procedure. At the end of the first stage, the stress amplitude decreased to nearly $0.0 \mathrm{MPa}$. Then, the decrease rate of stress amplitude became smaller at the next three stages, and the value remained at $-50.0 \mathrm{MPa}$ as the number of load cycle reached at 1.1 million.

2.4. Results after Strengthening. CFRP plates were then bonded to the U-rib plates to strengthen both cracked welded joints, i.e., D2 and D3. Figure 7 shows actual view 


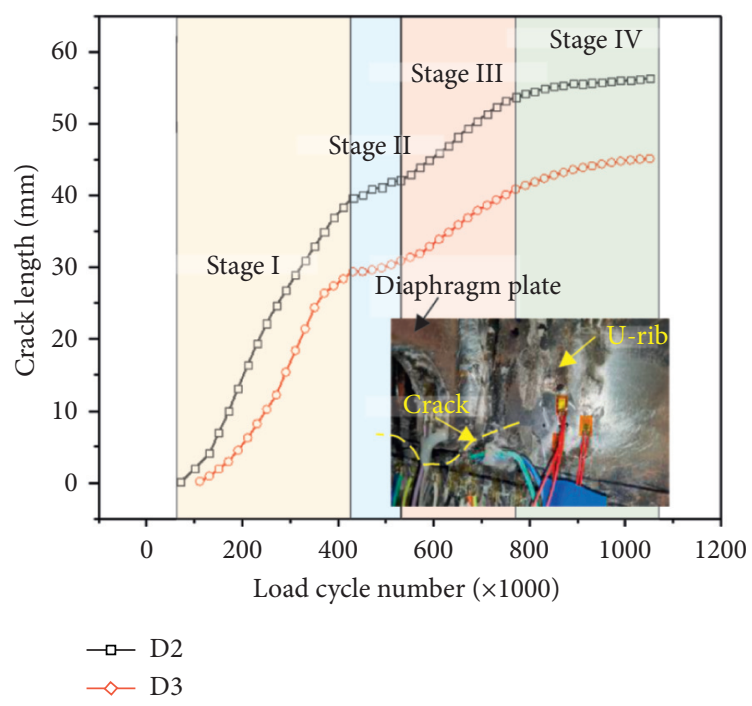

Figure 5: Curves of crack length with load cycle number.

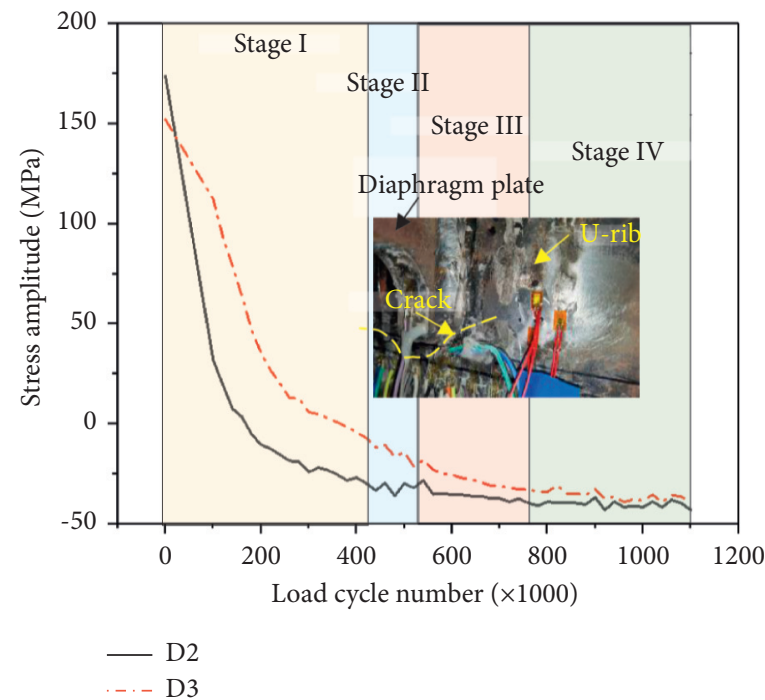

FIgURE 6: Curves of stress amplitude with load cycle number.

and strengthening scheme by CFRP plates. As shown in the figure, two square CFRP plates were attached to the cracked U-rib plates on both sides of diaphragm plate using one layer of epoxy resin adhesive as thick as $2.0 \mathrm{~mm}$. According to the shape and dimension of crack and construction space, the side length and thickness of the CFRP plates were $70 \mathrm{~mm}$ and $10 \mathrm{~mm}$, respectively.7-day maintenance was then carried out after bonding CFRP plates.

Static-load test was first carried out to verify the effect strengthened with CFRP plates. Table 2 presents stress of typical points as the static load reached at $260 \mathrm{kN}$ before and after strengthening. As shown in the table, the absolute value of compressive stress at D2-3 and D3-3 reduced by $13 \mathrm{MPa}$ and $12 \mathrm{MPa}$, where the falling rate reached at $30.2 \%$ and $30.8 \%$, respectively. The absolute value of tensile stress on the edge of arch gap, i.e., D2-1 and D3-1, increased $17 \mathrm{MPa}$ and $34 \mathrm{MPa}$ with the increasing rate as great as $28.8 \%$ and $36.2 \%$, respectively. Above consequences indicated that the involvement of CFRP plates at the cracked positions reduced stress intensity of U-rib plates near cracks, while tensile stress at the arch gap of diaphragm plates magnified causing greater risk of cracking.

The measured stress by D2-1 and D3-1 were applied to evaluate the strengthening effect of reducing stress near crack tips, which is shown in Table 2 either. As shown in the table, the stress at these two points reduced significantly after strengthening. The stress measured by D2-12 and D3-12 decreased by $74 \mathrm{MPa}$ and $67 \mathrm{MPa}$, whose reducing rate were $37.6 \%$ and $36.8 \%$, respectively. It indicated that stress intensity surrounding crack tips decreased after attachment of CFRP plates. In addition, fatigue test was carried out for 800 thousand cycles with the same loading scheme, and it was found that the length of existing cracks kept consistent and no new cracks occurred during the test.

D6-3 and D7-3 were used to verify the effect from the bonding CFRP plates to relieve stress at neighboring welded 


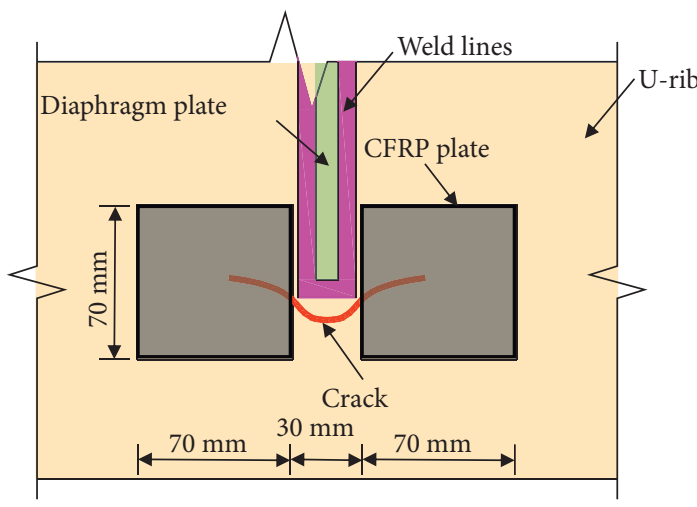

(a)

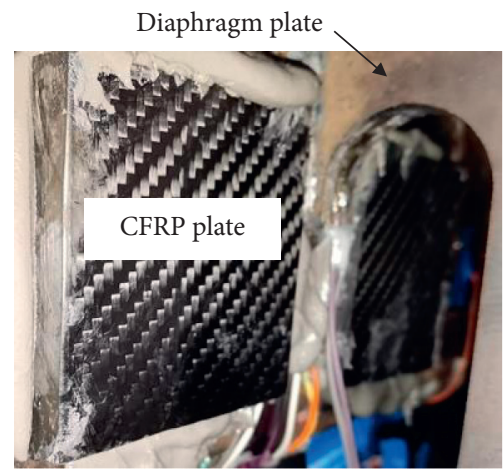

(b)

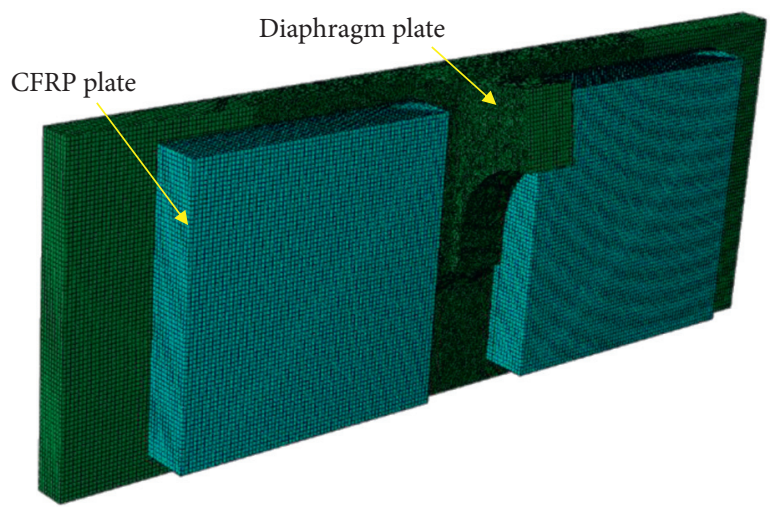

(c)

FIgURE 7: Actual view, diaphragm drawing and numerical model of CFRP plates. (a) Strengthening scheme. (b) Actual view. (c) Numerical model.

TABLE 2: Static-load stress before and after strengthening.

\begin{tabular}{lcccc}
\hline \multirow{2}{*}{ Welded joint } & Strain gauge & \multicolumn{2}{c}{ Stress $(\mathrm{MPa})$} & \multicolumn{2}{c}{ Variation rate of absolute value } \\
& & Before strengthening & After strengthening & $28.8 \%$ \\
D2 & D2-1 & 59.0 & 76.0 & $-30.2 \%$ \\
& D2-3 & -43.0 & -30.0 & $-37.6 \%$ \\
D2-12 & 197.0 & 123.0 & $36.2 \%$ \\
& D3-1 & 94.0 & 128.0 & $-30.8 \%$ \\
D6 & D3-3 & -39.0 & -27.0 & $-36.8 \%$ \\
D7 & D3-12 & 182.0 & 115.0 & $-3.41 \%$ \\
\hline
\end{tabular}

joints. As shown in Table 2, the absolute value of compressive stress at these two positions reduced with small range, whose reduction rate for D6-3 and D7-3 were only $3.4 \%$ and $10.8 \%$. As fatigue cracking has significant local behavior, it indicated that strengthening the cracked position had low influence to reduce fatigue load effect on the neighboring welded joints.

\section{Numerical Model of FRP-Strengthening Schemes}

3.1. Finite Model of OSD Specimen. A multiple-scale finite element model (M-Fem) was established and created to simulate the fatigue behavior before and after reinforcement by attaching CFRP plates. To improve calculation efficiency, a sub-model technique was used to simulate and link the global and local action of OSD specimen. A commercial finite element software of ABAQUAS was used to create M-Fem and simulate fatigue behavior of the experimental specimen, which is shown in Figure 8. The geometric dimension of M-Fem was similar with the specimen of OSD. S4R shell unites were used to simulate the global model with a mesh dimension of $10 \mathrm{~mm}$. A Rib-to-diaphragm welded joint with similar position of D2 and D3 was simulated as the local model. The geometric dimension of the local model at $\mathrm{X}, \mathrm{Y}$ and $\mathrm{Z}$ direction were $300 \mathrm{~mm}, 380 \mathrm{~mm}$ and $214 \mathrm{~mm}$, respectively. A mixture of $\mathrm{C} 3 \mathrm{D} 8 \mathrm{R}$ hexahedral units and C3D10 tetrahedral units was used to simulate behavior of the 


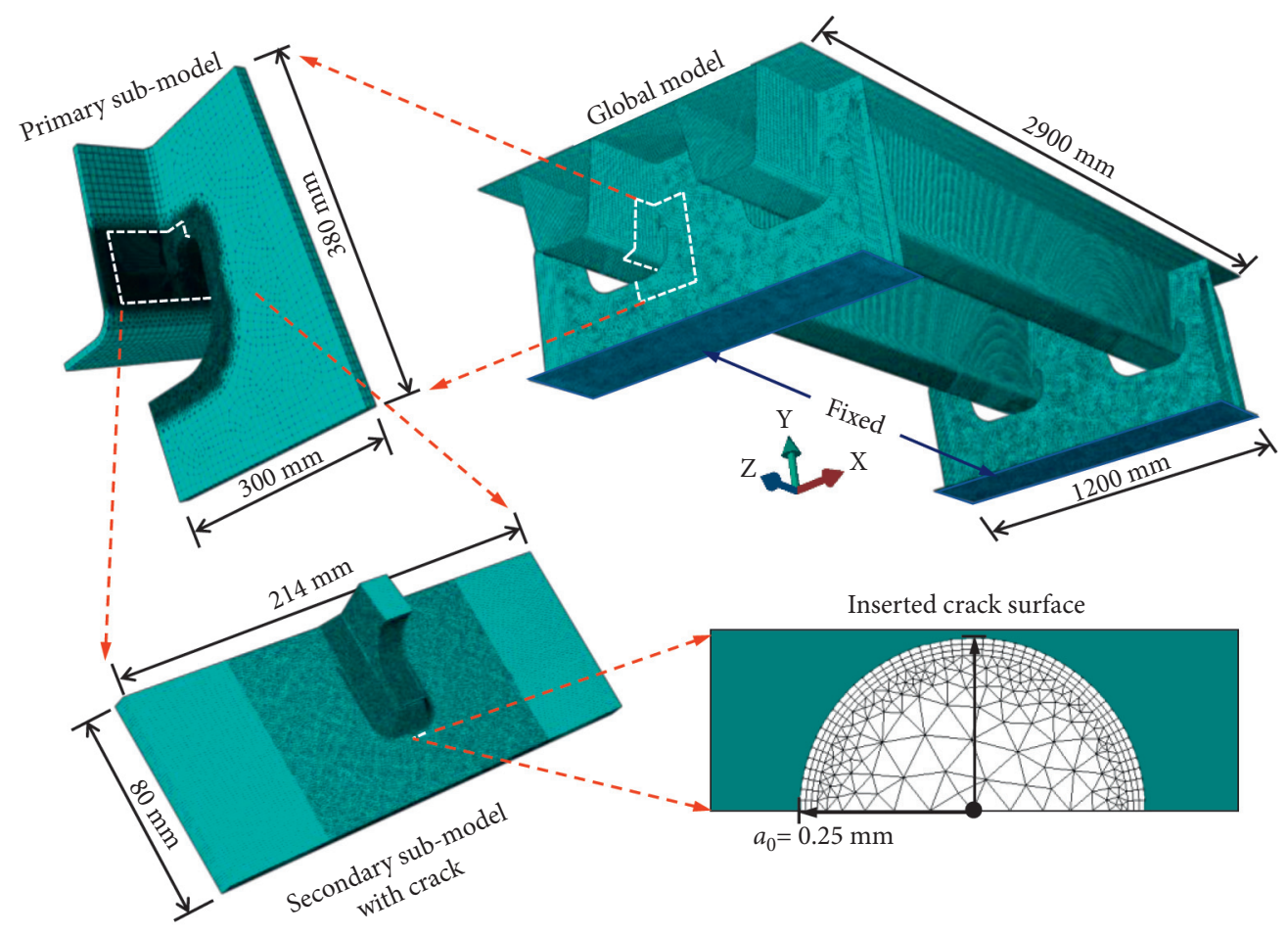

FIGURE 8: Finite element model of the experimental specimen.

local model. Distant region from cracking position was simulated by C3D8R hexahedral units with mesh unit of $10 \mathrm{~mm}$, when suburb region was simulated by C3D10 tetrahedral units with mesh unit of $1 \mathrm{~mm}$. These meshes between above two regions were connected with distorted C3D10 tetrahedral units.

The elastic modulus and passion ration were selected as $206 \mathrm{GPa}$ and 0.3, respectively. Fixed constraints were applied on the bottom flange of two diaphragms to simulate boundary conditions of the specimen. A uniform load with an acting region of $400 \mathrm{~mm} \times 400 \mathrm{~mm}$, similar to geometric dimension of the rubber mat in the fatigue test, was used to simulate the experimental load. The intensity of uniform load was calculated and obtained by dividing the corresponding experimental load by the area of acting region. To validate the accuracy of the FE model, analysis was conducted to obtain stress at different measured points in the uncracked specimen. Table 3 compares the FE stresses at D2-1, D2-2, D2-3 and D24 with those measured at the beginning of fatigue tests, where good agreement was observed.

3.2. Crack Propagation Simulation. Crack propagation was simulated by establishing a more fined model embed into the Finite element model of OSD specimen. The refined model was operated by FE software FRANC 3D, where the dimension of the model in the $\mathrm{Y}$ and $\mathrm{Z}$ directions were $80 \mathrm{~mm}$ and $214 \mathrm{~mm}$, respectively. A semicircular virtual crack with zero volume and radius of $0.25 \mathrm{~mm}\left(a_{0}\right)$ was inserted at the weld toe of the U-rib in the secondary sub-model, which is shown in Figure $7(\mathrm{c})$. Based on the previously proposed macrocrack propagation theories, the virtual crack length grown step by step until reaching the critical length $a_{\mathrm{c}}$.

3.3. Simulation of Strengthening with CFRP. The attachment of CFRP plates by bonding was simulated by introducing composite structure containing glue layer to the cracked model of the tested specimen. Both CFRP plates and glue layer were simulated by orthotropic elastic material. The model of the composite structure was simulated by C3D 8 hexahedral unit with mesh size of $1 \mathrm{~mm}$. The composite model was attached to OSD model by Tie-binding technique. The dimension and material parameters were the same as the tested specimen. In the numerical model, the elastic modulus and Poison's ratio of CFRP and glue layer shown in Table 4.

\section{Parameter Analysis on Fatigue Property Strengthened by CFRP}

4.1. Calculation of SIFs. Theory of linear elastic fracture mechanics was often applied to evaluate crack propagation, where the stress distribution around crack tips was frequently assessed by Stress Intensity Factor (SIF). Under condition of multiple loading actions, method of interaction integration was frequently involved to calculate SIF. For elastic material, the SIFs equal to rate of energy release $K$, which can be described by J-integral and formulated as follows:

$$
\begin{aligned}
\mathbf{J}_{\text {int }} & =\left[J_{\text {int }}^{\mathrm{I}}, J_{\text {int }}^{\mathrm{II}}, J_{\mathrm{int}}^{\mathrm{III}}\right]^{\mathrm{T}}, \\
\mathbf{K} & =4 \pi \mathbf{B} \cdot \mathbf{J}_{\text {int }},
\end{aligned}
$$


TABLE 3: Comparison between calculation and experimental stress.

\begin{tabular}{lccc}
\hline Position & Experimental result $(\mathrm{MPa})$ & Calculation result $(\mathrm{MPa})$ & Rate of deviation \\
\hline D2-1 & 174.0 & 180.0 & $3.3 \%$ \\
D2-2 & 194.0 & 200.0 & $3.0 \%$ \\
D2-3 & 177.0 & 181.0 & $1.6 \%$ \\
D2-4 & 245.0 & 243.0 & $0.8 \%$ \\
\hline
\end{tabular}

TABLE 4: Elastic modulus and Poison's ratio of CFRP and glue layer.

\begin{tabular}{lcc}
\hline Name & Elastic modulus $(\mathrm{MPa})$ & Poison's ratio \\
\hline CFRP & $2.5 \times 10^{5}$ & 0.3 \\
Glue layer & $6.0 \times 10^{3}$ & 0.38 \\
\hline
\end{tabular}

where $B$ denotes pre-logarithmic energy factor matrix, $\mathbf{J}_{\text {int }}$ is J-integral described by components formed by I-, II -and IIItype crack presented by following formulations:

$$
\begin{aligned}
& J_{\text {int }}^{\alpha}=\lim _{\Gamma \longrightarrow 0} \int_{\Gamma} \mathbf{n} \cdot \mathbf{M}^{\alpha} \cdot \mathbf{q} d \Gamma, \\
& \mathbf{M}^{\alpha}=\sigma: \varepsilon_{\mathrm{aux}}^{\alpha} \mathbf{I}-\boldsymbol{\sigma} \cdot\left(\frac{\partial \mathbf{u}}{\partial \mathbf{x}}\right)^{\alpha}-\boldsymbol{\sigma}_{\mathrm{aux}}^{\alpha} \cdot \frac{\partial u}{\partial x},
\end{aligned}
$$

where subscript of aux denotes three crack types naming I-, II- and III-type crack, $\Gamma \longrightarrow 0$ presents procedure of crack shrinking along $\Gamma$ contour, $\Gamma$ describes contour along the normal plane of the crack front where the beginning and the ending surface are the bottom and top crack surface, receptively.

Then, $\lambda(s)$ was introduced to simulate the crack propagation and formulated as follows:

$$
\bar{J}_{\text {int }}^{\alpha}=\int_{L} J_{\text {int }}^{\alpha}(s) \lambda(s) \mathrm{d} s=\int_{L} \lambda(s) \mathbf{n} \cdot \mathbf{M}^{\alpha} \cdot \mathbf{q d A},
$$

where $L$ donates front edge of simulated crack, $d \mathrm{~A}$ is derivative of surface elements on a tiny tubular surface surrounding the crack tip, $\boldsymbol{n}$ is exterior normal of $d \mathrm{~A}, \boldsymbol{q}$ is local nominal of virtual crack propagation direction.

In (3), $\lambda(s)$ requires dissociation by interpolation function to calculation $J_{\text {int }}^{\alpha}$ at each point $\mathrm{P}$ along the front edge of cracks. The calculation formulation is shown in follows:

$$
\lambda(s)=N^{Q}(s) \lambda^{Q},
$$

where $\lambda^{Q}=1$ at position of $\mathrm{P}$ and $\lambda^{Q}=0$ at other positions.

Applying (4) into (3), the J-internal at each point $\mathrm{P}$ can be formulated by (5). Finally, the calculation result of $J_{\text {int }}^{\alpha P}$ were put into (1) and SIF was calculated and obtained.

$$
J_{\text {int }}^{\alpha P}=\frac{\bar{J}_{\text {int }}^{\alpha P}}{\int_{L} N^{P} \mathrm{~d} s}
$$

As length and profile of cracks kept variating, curve of SIF with normalized distance along crack front was often applied to deal with the cracking problem. Figure 9 presents normalized curves of SIF distribution along crack length before and after strengthening. In the figure, points A and B indicated crack tips at two sides, and point $\mathrm{C}$ was the midpoint at the crack. As shown in the figure, the profile of two curves is similar while two peak points move to the deep from the surface after reinforcement. In addition, the peak value of the curve reduces from $550 \mathrm{MPa}^{1 / 2}$ to $317 \mathrm{MPa}^{1 / 2}$. Table 4 shows the calculated SIF at three points before and after strengthening.

4.2. Elastic Modulus of Glue Layer. It was investigated elastic modulus of glue (EMG) layer affected strengthening effect of FRP plates and sheets on fatigue and static-load property of steel structures. In this section, six different values of EMG, as shown in Table 5, were applied into the FE model of the CFRP-strengthened OSD specimen. The elastic modulus of CFRP plates (EMC) was defined as $0.25 \mathrm{GPa}$, and the side dimension of square CFRP plates was defined as $70 \mathrm{~mm}$. The calculation results of SIF at A, B and C points were shown in Table 5 either.

As shown in the table, with increase of EMG from 1000 $\mathrm{MPa}$ to $6000 \mathrm{MPa}$, the value of SIF at point A reduced from $414 \mathrm{MPa} \cdot \mathrm{mm}^{1 / 2}$ to $243 \mathrm{MPa} \cdot \mathrm{mm}^{1 / 2}$. Post-strengthening reducing rate of SIFs was introduced to evaluate influence of EMG on strengthening effect. It is presented from the table that the post-strengthening reducing rate was $24.7 \%$ and $55.8 \%$, respectively, for EMG equaling to $1000 \mathrm{MPa}$ and 6000 $\mathrm{MPa}$. In other words, the post-strengthening reducing rate of SIFs at point A increased by about $125.9 \%$ with EMG grew from $1000 \mathrm{MPa}$ to $6000 \mathrm{MPa}$. Increase of EMG also reduce SIFs at points $\mathrm{B}$ and $\mathrm{C}$, where the post-strengthening reducing rate of SIFs at these two points increased by $119.8 \%$ and $85.8 \%$.

4.3. Elastic Modulus of CFRP Material. Influence of elastic modulus of CFRP material (EMC) was evaluated by varying EMC in the FE model of the CFRP-strengthened OSD specimen. In the FE model, side dimension of square GFRP plates as well as EMG were fixed as $70 \mathrm{~mm}$ and $6000 \mathrm{MPa}$. Having calculate and obtain the SIF of type-I crack distribution along crack length, the SIF at points $\mathrm{A}, \mathrm{B}$ and $\mathrm{C}$ were also compared under conditions of EMC, where the computation results are shown in Table 6.

As shown in the table, the growth of EMC reduced SIFs at above three positions of cracks partially. Although the calculated results of SIFs under three different EMC decreased significantly compared with those without 


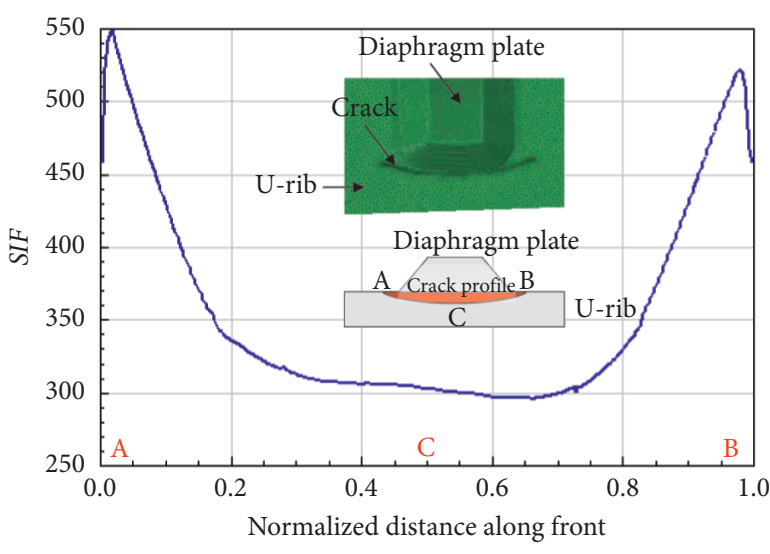

(a)

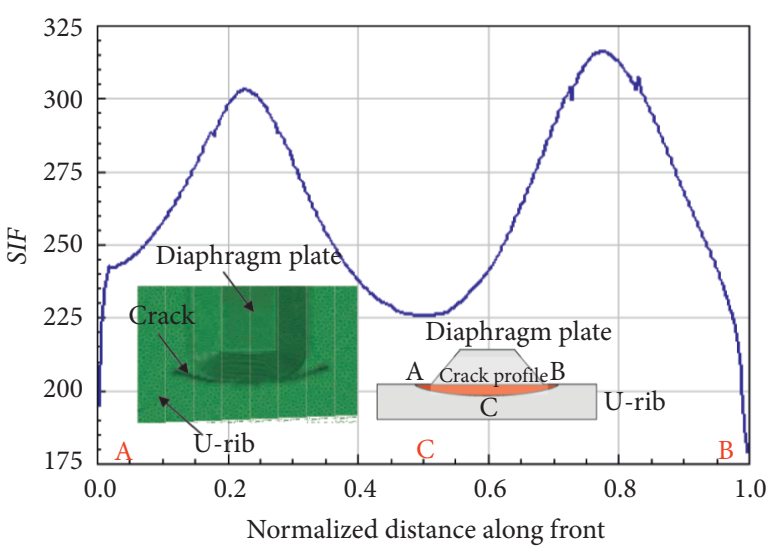

(b)

Figure 9: Normalized curves of SIF distribution along crack length before and after strengthening. (a) Before strengthening. (b) After strengthening.

TABLE 5: Calculation results of SIF under different EMG.

\begin{tabular}{|c|c|c|c|c|c|c|}
\hline \multirow{2}{*}{ EMG (MPa) } & \multicolumn{2}{|c|}{ Point A } & \multicolumn{2}{|c|}{ Point B } & \multicolumn{2}{|c|}{ Point B } \\
\hline & SIF & Reducing rate & SIF & Reducing rate & SIF & Reducing rate \\
\hline $1.0 \times 10^{3}$ & 414 & $24.7 \%$ & 386 & $26.2 \%$ & 262 & $14.1 \%$ \\
\hline $2.0 \times 10^{3}$ & 357 & $35.1 \%$ & 335 & $35.9 \%$ & 249 & $18.4 \%$ \\
\hline $3.0 \times 10^{3}$ & 317 & $42.4 \%$ & 294 & $43.8 \%$ & 240 & $21.3 \%$ \\
\hline $4.0 \times 10^{3}$ & 282 & $48.7 \%$ & 265 & $49.3 \%$ & 234 & $23.3 \%$ \\
\hline $5.0 \times 10^{3}$ & 263 & $52.2 \%$ & 238 & $54.5 \%$ & 228 & $25.2 \%$ \\
\hline $6.0 \times 10^{3}$ & 243 & $55.8 \%$ & 222 & $57.6 \%$ & 225 & $26.2 \%$ \\
\hline
\end{tabular}

TABLE 6: Calculation results of SIF under different EMC.

\begin{tabular}{|c|c|c|c|c|c|c|}
\hline \multirow{2}{*}{$\mathrm{EMC}(\mathrm{MPa})$} & \multicolumn{2}{|c|}{ Point A } & \multicolumn{2}{|c|}{ Point B } & \multicolumn{2}{|c|}{ Point B } \\
\hline & SIF & Reducing rate & SIF & Reducing rate & SIF & Reducing rate \\
\hline $1.00 \times 10^{5}$ & 281 & $48.9 \%$ & 264 & $49.5 \%$ & 241 & $21.0 \%$ \\
\hline $1.30 \times 10^{5}$ & 268 & $51.3 \%$ & 252 & $51.8 \%$ & 237 & $22.3 \%$ \\
\hline $1.60 \times 10^{5}$ & 260 & $52.7 \%$ & 244 & $53.3 \%$ & 233 & $23.6 \%$ \\
\hline $1.90 \times 10^{5}$ & 254 & $53.8 \%$ & 237 & $54.7 \%$ & 230 & $24.6 \%$ \\
\hline $2.20 \times 10^{5}$ & 247 & $55.1 \%$ & 230 & $56.0 \%$ & 227 & $25.6 \%$ \\
\hline $2.50 \times 10^{5}$ & 243 & $55.8 \%$ & 222 & $57.6 \%$ & 225 & $26.2 \%$ \\
\hline
\end{tabular}

strengthening, the influence of EMC was not as great as EMG showing smaller post-strengthening reducing rate of SIFs. Post-strengthening reducing rate of SIFs (PRR) was used to compare the influence from EMC. Although the EMC increased to 2.5 times, from $100 \mathrm{GPa}$ to $250 \mathrm{GPa}$, the value of PRR increased by only $6.90 \%, 8.10 \%$ and $5.20 \%$ for above three positions of cracks.

4.4. Dimensions of CFRP Plates. The side length of square CFRP plates was varied to assess the influence of dimensions of CFRP plates on SIFs. Three different values of side length of square CFRP plates were defined in the FE model, which is show in Table 7. To eliminate the influence of positions of square CFRP plates, two vertical sides of each square CFRP plates was fixed, which is presented in Figure 10. As shown in the figure, one fixed side met with the line of weld toe, and the other fixed side met with the bending line of the U-rib plates. In addition, the value of EMC and EMG were defined as constant, i.e., $6.0 \mathrm{GPa}$ and $250.0 \mathrm{GPa}$, respectively.

The results of calculated SIF and PRR are shown in Table 7 either. As shown in the table, the value of SIF at all three points fluctuates in a small range, as the side length of square CFRP plates increased from $55 \mathrm{~mm}$ to $70 \mathrm{~mm}$. Similarly, the value of PRR increased by $-0.9 \%, 0.4 \%$ and $6.9 \%$, respectively.

\section{Discussion}

As mentioned previously, three parameters of CFRP strengthening scheme have different influence on fatigue performance of cracked OSD specimen, which can be profiled by two parameters, i.e., SIF and PRR at three typical points. Among these three parameters, the EMG had the most significant influence on reducing SIF and PRR. In other words, increasing EMG is the most efficient way to remit risk 
TABLE 7: Calculation results of SIF under different dimensions of CFRP plates.

\begin{tabular}{|c|c|c|c|c|c|c|}
\hline \multirow{2}{*}{ Side length $(\mathrm{mm})$} & \multicolumn{2}{|c|}{ Point A } & \multicolumn{2}{|c|}{ Point B } & \multicolumn{2}{|c|}{ Point B } \\
\hline & SIF & Reducing rate & SIF & Reducing rate & SIF & Reducing rate \\
\hline 55 & 238 & $56.7 \%$ & 224 & $57.2 \%$ & 246 & $19.3 \%$ \\
\hline 57.5 & 235 & $57.3 \%$ & 223 & $57.4 \%$ & 241 & $21.0 \%$ \\
\hline 60.0 & 235 & $57.3 \%$ & 221 & $57.7 \%$ & 236 & $22.6 \%$ \\
\hline 62.5 & 236 & $57.1 \%$ & 222 & $57.6 \%$ & 232 & $23.9 \%$ \\
\hline 65.0 & 237 & $56.9 \%$ & 222 & $57.6 \%$ & 229 & $24.9 \%$ \\
\hline 67.5 & 238 & $56.7 \%$ & 221 & $57.7 \%$ & 227 & $25.6 \%$ \\
\hline 70.0 & 243 & $55.8 \%$ & 222 & $57.6 \%$ & 225 & $26.2 \%$ \\
\hline
\end{tabular}

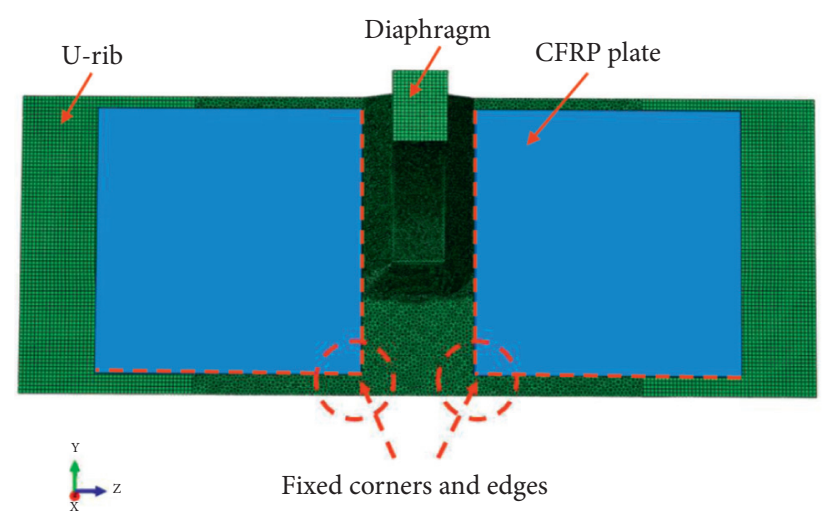

Figure 10: Fixed corners and edges of CFRP plates.

of fatigue failure strengthened by CFRP plates. In addition, the growth of EMC has also fine effect to increase resistance to fatigue damage. In contrast, increasing plane sizes of CFRP plates has ineffective impact to improve strengthening efficiency.

The propagation or development of crack depends on stress intensity at crack tips or midpoint of crack surface. The strengthening principle by bonding attachment of CFRP plates is to provide external constraint on crack growth, reducing stress intensity along crack surface. As the elastic modulus and thickness of the glue layer is much smaller than steel plates and CFRP plates, the mechanical property of sandwiched glue layer has the most significant impact on the deformation or stress of steel plated induced by crack opening. Consequently, the increasing of the EMG can provide more serious restriction to the crack, reducing the value of SIFs as well as risk of crack development. It is also certain that the increasing of the EMC and the plane size of CFRP plates can enhance the constraint on the glue layer. Therefore, these two parameters can influence the SIFs within a relatively small range.

\section{Conclusions}

To evaluate the strengthening effect of CFRP plates on fatigue performance of rib-to-diaphragm welded joints of OSD specimen, constant-amplitude fatigue test and numerical evaluation were carried out for a full-scale OSD specimen. Based on the experiment-calibrated numerical simulation and assessment, the efficiency of strengthening scheme from three strengthening parameters, i.e. i.e., EMG, EMC and plane size of CFPR plates, was compared and discussed, the main conclusions can be drawn and described as follows:

1. Under action of repeating load on the middle span of deck plates, fatigue cracking occurs with a high probability at the rib-to-diaphragm welded joints, initiating at the intersection between the weld toe and diaphragm hole. The propagation procedure, until number of loading cycle reaching at 1.1 million, can be divided into four stages according to the growth rate of crack, whose magnitude in the first and third stage is relatively large. The growth rate of crack decreases in the $4^{\text {th }}$ stage with extension of number of loading cycle, and the magnitude approaches to zero at the end of the $4^{\text {th }}$ stage. In addition, stress at the initiation region decreases constantly with extension of crack length, indicating significant stress relaxation of structure has been caused by cracking.

2. The attachment of CFRP plates by bonding on the surface of cracked plates shows showing satisfying strengthening effect, reducing stress response at cracked region by more than $30 \%$. Fatigue-test results shows good effect on preventing crack propagation. Cracks did not develop even if the number of loading cycle after strengthening arrived at 0.8 million. Results of SIFs calculated by numerical model showed big 
drop after strengthening with reduction rate more than $35 \%$ and $18 \%$ at two crack tips and crack midpoint, respectively.

3. The strengthening efficiency, which was profiled by reduction rate of SIFs, is influenced by EMG, EMC and plane size of CFPR plates with different degrees. With the increase of above three factors, the reduction rate of SIFs at two crack tips and crack midpoint decreases, where the value of EMG and EMC is the top two susceptive factor increasing strengthening efficiency. Therefore, scheme with high value of EMG and EMC is recommended to strengthen cracked OSD specimens, where the plan size of CFRP plates can just satisfy minimum bonding length.

\section{Data Availability}

The data used to support the findings of this study are included within the article.

\section{Conflicts of Interest}

The authors declare that there are no conflicts of interest regarding the publication of this paper.

\section{Acknowledgments}

The authors acknowledge funding from the National Natural Science Foundation [Grant No. 51508251], the Jiangsu Natural Science Foundation [Grant No. BK20211003], the project of Six Talent Peaks in Jiangsu Province [Grant No. jz062], and the Jinling Institute of Technology High-level Personnel Work Activation Fee to Fund Projects [Grant No. jit-b-201614].

\section{References}

[1] Z. Xiao, K. Yamada, S. Ya, and X. Zhao, "Stress analyses and fatigue evaluation of rib-to-deck joints in steel orthotropic decks," International Journal of Fatigue, vol. 30, no. 8, pp. 1387-1397, 2008.

[2] Y. Deng, Y. Liu, D. M. Feng, and A. Q. Li, "Investigation of fatigue performance of welded details in long-span steel bridges using long-term monitoring strain data," Structural Control and Health Monitoring, vol. 22, no. 11, pp. 1343-1358, 2015.

[3] K. Nishikawa, J. Murakoshi, and T. Matsuki, "Study on the fatigue of steel highway bridges in Japan," Construction and Building Materials, vol. 12, no. 2-3, pp. 133-141, 1998.

[4] J. Toribio, V. Kharin, F. J. Ayaso et al., "Numerical and experimental analyses of the plasticity-induced fatigue crack growth in high-strength steels," Construction and Building Materials, vol. 25, no. 10, pp. 3935-3940, 2011.

[5] H. B. Sim and C. M. Uang, "Stress analyses and parametric study on full-scale fatigue tests of rib-to-deck welded joints in steel orthotropic decks," Journal of Bridge Engineering, vol. 17, no. 5, pp. 765-773, 2012.

[6] Y. Zhiyuan, B. Ji, Z. Fu, and H. Ge, "Fatigue performance of cracked rib-deck welded joint retrofitted by ICR technique," International Journal of Steel Structures, vol. 16, no. 3, pp. 735-742, 2016.
[7] C. Miki and T. Konishi, "Retrofit engineering for steel bridge structures in Japan," in Proceedings of the IABSE Symposium Report, pp. 49-79, International Association for Bridge and Structural Engineering, Zurich, Switzerland, September 2007.

[8] Z. Fu, B. Ji, X. Kong, and X. Chen, "Grinding treatment effect on rib-to-roof weld fatigue performance of steel bridge decks," Journal of Constructional Steel Research, vol. 129, pp. 163-170, 2017.

[9] Y. Ochi, K. Masaki, T. Matsumura, and T. Sekino, "Effect of shot-peening treatment on high cycle fatigue property of ductile cast iron," International Journal of Fatigue, vol. 23, no. 5, pp. 441-448, 2001.

[10] P. Colombi, A. Bassetti, and A. Nussbaumer, "Analysis of cracked steel members reinforced by pre-stress composite patch," Fatigue and Fracture of Engineering Materials and Structures, vol. 26, no. 1, pp. 59-66, 2003.

[11] S. C. Jones and S. A. Civjan, "Application of fiber reinforced polymer overlays to extend steel fatigue life," Journal of Composites for Construction, vol. 7, no. 4, pp. 331-338, 2003.

[12] M. Tavakkolizadeh and H. Saadatmanesh, "Fatigue strength of steel girders strengthened with carbon fiber reinforced polymer patch," Journal of Structural Engineering, vol. 129, pp. 186-196, 2003.

[13] M. Bocciarelli, P. Colombi, G. Fava, and C. Poggi, "Fatigue performance of tensile steel members strengthened with CFRP plates," Composite Structures, vol. 87, no. 4, pp. 334-343, 2009.

[14] B. Täljsten, C. S. Hansen, and J. W. Schmidt, "Strengthening of old metallic structures in fatigue with prestressed and nonprestressed CFRP laminates," Construction and Building Materials, vol. 23, no. 4, pp. 1665-1677, 2009.

[15] F. Alemdar, A. B. Matamoros, C. R. Bennett, R. B. Gonzalez, and S. T. Rolfe, "Improved method for bonding CFRP overlays to steel for fatigue repair," in Proceedings of the Structures Congress 2011, pp. 133-144, American Society of Civil Engineers, Las Vegas, NV, USA, April 2011.

[16] F. Alemdar, R. Gangel, A. Matamoros et al., "Use of CFRP overlays to repair fatigue damage in steel plates under tension loading," Journal of Composites for Construction, vol. 18, no. 4, Article ID 04013052, 2014.

[17] L. L. Hu, X. L. Zhao, and P. Feng, "Fatigue behavior of cracked high-strength steel plates strengthened by CFRP sheets," Journal of Composites for Construction, vol. 20, no. 6, Article ID 04016043, 2016.

[18] M. Mohajer, M. Bocciarelli, P. Colombi, A. Hosseini, A. Nussbaumer, and E. Ghafoori, "Irreversible cyclic cohesive zone model for prediction of mode I fatigue crack growth in CFRP-strengthened steel plates," Theoretical and Applied Fracture Mechanics, vol. 110, Article ID 102804, 2020.

[19] Y. Doroudi, D. Fernando, H. Zhou, V. T. Nguyen, and E. Ghafoori, "Fatigue behavior of FRP-to-steel bonded interface: an experimental study with a damage plasticity model," International Journal of Fatigue, vol. 139, Article ID 105785, 2020.

[20] H.-T. Wang, G. Wu, and J.-B. Jiang, "Fatigue behavior of cracked steel plates strengthened with different CFRP systems and configurations," Journal of Composites for Construction, vol. 20, Article ID 04015078, 2015.

[21] Y. Kasper, M. Albiez, T. Ummenhofer et al., "Application of toughened epoxy-adhesives for strengthening of fatiguedamaged steel structures," Construction and Building Materials, vol. 275, Article ID 121579, 2021.

[22] L. Tong, Q. Yu, and X.-L. Zhao, "Experimental study on fatigue behavior of butt-welded thin-walled steel plates 
strengthened using CFRP sheets," Thin-Walled Structures, vol. 147, Article ID 106471, 2020.

[23] H. Nakamura, W. Jiang, H. Suzuki, K. I. Maeda, and T. Irube, "Experimental study on repair of fatigue cracks at welded web gusset joint using CFRP strips," Thin-Walled Structures, vol. 47, no. 10, pp. 1059-1068, 2009.

[24] T. Chen, X.-L. Zhao, X.-L. Gu, and Z.-G. Xiao, "Numerical analysis on fatigue crack growth life of non-load-carrying cruciform welded joints repaired with FRP materials," Composites Part B: Engineering, vol. 56, pp. 171-177, 2014.

[25] J. Liu, T. Guo, D. Feng, and Z. Liu, "Fatigue performance of rib-to-deck joints strengthened with FRP angles," Journal of Bridge Engineering, vol. 23, no. 9, Article ID 04018060, 2018.

[26] S. Chataigner, M. Wahbeh, D. Garcia-Sanchez et al., "Fatigue strengthening of steel bridges with adhesively bonded CFRP laminates: case study," Journal of Composites for Construction, vol. 24, Article ID 05020002, 2020.

[27] Z. Jie, W. Wang, C. Chen, and K. Wang, "Local approaches and XFEM used to estimate life of CFRP repaired cracked welded joints under fatigue loading," Composite Structures, vol. 260, Article ID 113251, 2021.

[28] A. Mohabeddine, J. A. F. O. Correia, P. A. Montenegro, and J. M. Castro, "Fatigue crack growth modelling for cracked small-scale structural details repaired with CFRP," ThinWalled Structures, vol. 161, Article ID 107525, 2021.

[29] Q. H. Zhang, C. Cui, Y. Z. Bu, Y. M. Liu, and H. W. Ye, "Fatigue tests and fatigue assessment approaches for rib-todiaphragm in steel orthotropic decks," Journal of Constructional Steel Research, vol. 114, pp. 110-118, 2015.

[30] BS EN 1991-2, Eurocode 1: Actions on Structures - Part 2: Traffic Loads on Bridges, European Committee for Standardization, Brussels, Belgium, 2003. 